\title{
Characterization of a novel embryonic stem cell line from an ICSI-derived blastocyst in the African green monkey
}

\author{
Nobuhiro Shimozawa ${ }^{1}$, Shinichiro Nakamura ${ }^{2}$, Ichiro Takahashi ${ }^{3}$, Masanori Hatori ${ }^{1,4}$ \\ and Tadashi Sankai ${ }^{1}$ \\ ${ }^{1}$ Tsukuba Primate Research Center (TPRC), National Institute of Biomedical Innovation (NIBIO), 1-1 Hachimandai, \\ Tsukuba, Ibaraki 305-0843, Japan, ${ }^{2}$ Research Center for Animal Life Science, Shiga University of Medical Science, \\ Seta Tsukinowa, Ohtsu, Shiga 520-2192, Japan, ${ }^{3}$ Department of Biomedical Resources, NIBIO, 7-6-8 Saito-Asagi, \\ Ibaraki, Osaka 567-0085, Japan and ${ }^{4}$ Graduate School of Comprehensive Human Sciences, University of Tsukuba, \\ 1-1-1 Tennodai, Tsukuba, Ibaraki 305-8577, Japan
}

Correspondence should be addressed to N Shimozawa; Email: shimo@nibio.go.jp

\begin{abstract}
Several cell types from the African green monkey (Cercopithecus aethiops), such as red blood cells, primary culture cells from kidney, and the Vero cell line, are valuable sources for biomedical research and testing. Embryonic stem (ES) cells that are established from blastocysts have pluripotency to differentiate into these and other types of cells. We examined an in vitro culture system of zygotes produced by ICSI in African green monkeys and attempted to establish ES cells. Culturing with and without a mouse embryonic fibroblast (MEF) cell monolayer resulted in the development of ICSI-derived zygotes to the blastocyst stage, while culturing with a buffalo rat liver cell monolayer yielded no development $(3 / 14,21.4 \%$ and $6 / 31,19.4 \%$ vs $0 / 23,0 \%$ respectively; $P<0.05)$. One of the nine blastocysts, which had been one of the zygotes co-cultured with MEF cells, formed flat colonies consisting of cells with large nuclei, similar to other primate ES cell lines. The African green monkey ES (AgMES) cells expressed pluripotency markers, formed teratomas consisting of three embryonic germ layer tissues, and had a normal chromosome number. Furthermore, expression of the germ cell markers CD9 and DPPA3 (STELLA) was detected in the embryoid bodies, suggesting that AgMES cells might have the potential ability to differentiate into germ cells. The results suggested that MEF cells greatly affected the quality of the inner cell mass of the blastocysts. In addition, AgMES cells would be a precious resource for biomedical research such as other primate ES cell lines.

Reproduction (2010) 139 565-573
\end{abstract}

\section{Introduction}

In vitro culturing is an important technique for effectively producing individuals from embryos that were manipulated in vitro. However, the in vitro culturing for the African green monkey (Cercopithecus aethiops) embryos has not been examined. In rhesus monkey embryos, co-culture with a buffalo rat liver (BRL) cell monolayer in CMRL-1066 has been utilized (Zhang et al. 1994, Nusser et al. 2001). On the other hand, mouse embryonic fibroblast (MEF) cells have been widely utilized for the establishment of embryonic stem (ES) cells, showing that MEF cells affect establishment of the ES cells from the inner cell mass (ICM), where develop to an individual in the future, of blastocyst. We therefore considered that MEF might also enhance the growth of African green monkey embryos cultured in vitro.

Primate ES cell lines were established in the rhesus monkey (Macaca mulatta) for the first time in 1995 (Thomson et al. 1995) and were subsequently established in the common marmoset (Callithrix jacchus) in 1996 (Thomson et al. 1996), in humans in 1998 (Thomson et al. 1998), and in the cynomolgus monkey (Macaca fascicularis) in 2001 (Suemori et al. 2001), aiming at utilization in biomedical research. In particular, application to regenerative medicine is expected. For this purpose, methods to induce ES cells to develop into specific differentiated cells have been examined, based on the pluripotency of ES cells, as well as their self-renewal and stable karyotype characteristics, which are important properties for not only regenerative or transplantation medicines but also research or inspection at the cytological level.

The red blood cells and primary culture cells from kidney of the African green monkey have been used for the inspection of measles infection and human polio vaccine production respectively. In addition, the Vero cell line established from the kidney of the monkey has been used to test viral infections and to introduce foreign genes. Furthermore, spontaneous systemic amyloidosis was 
Table 1 Attempt to establish embryonic stem (ES) cell lines in African green monkeys.

\begin{tabular}{|c|c|c|c|c|c|c|c|c|}
\hline & $\begin{array}{c}\text { Culture of } \\
\text { zygotes }\end{array}$ & $\begin{array}{l}\text { Number of } \\
\text { blastocysts }\end{array}$ & $\begin{array}{l}\text { Treatment of } \\
\text { blastocysts }^{\mathrm{a}}\end{array}$ & $\begin{array}{l}\text { Number of } \\
\text { outgrowths }\end{array}$ & $\begin{array}{l}\text { Passage } \\
\text { methods }\end{array}$ & $\begin{array}{c}\text { Colony } \\
\text { appearance }\end{array}$ & $\begin{array}{l}\text { Passage } \\
\text { methods }\end{array}$ & $\begin{array}{c}\text { Number of ES } \\
\text { cell lines } \\
\text { established }\end{array}$ \\
\hline I & \multirow[t]{2}{*}{$\begin{array}{l}\text { With MEF } \\
\text { monolayer }\end{array}$} & 1 & $\begin{array}{l}\text { Removal of ZP } \\
\text { and TE }\end{array}$ & 1 & $\begin{array}{l}\text { Enzyme and } \\
\text { needles }\end{array}$ & 1 & $\begin{array}{c}\text { Enzyme and } \\
\text { needles }\end{array}$ & 1 \\
\hline II & & 2 & Removal of ZP & 2 & $\begin{array}{c}\text { Enzyme and } \\
\text { needles }\end{array}$ & 1 & $\begin{array}{l}\text { Enzyme and } \\
\text { pipetting }\end{array}$ & 0 \\
\hline III & \multirow[t]{2}{*}{$\begin{array}{l}\text { Without cell } \\
\text { monolayer }\end{array}$} & 3 & $\begin{array}{l}\text { Removal of ZP } \\
\text { and TE }\end{array}$ & 1 & $\begin{array}{l}\text { Enzyme and } \\
\text { pipetting }\end{array}$ & 1 & $\begin{array}{c}\text { Enzyme and } \\
\text { pipetting }\end{array}$ & 0 \\
\hline IV & & 3 & Removal of ZP & 0 & - & - & - & - \\
\hline
\end{tabular}

${ }^{\mathrm{a} Z P}$, zona pellucida; $\mathrm{TE}$, trophectoderm.

recently reported in this monkey (Nakamura et al. 2008). The African green monkey and the differentiated cells derived from African green monkey ES (AgMES) cells may help to elucidate the mechanism of amyloidosis in humans and contribute to the treatment. Those unique characteristics show that the cells of the monkey are very valuable for biomedical research and testing.

ES cells may be useful as a source of cells with the same genetic background, even if we do not collect them from living individuals. In short, we could reduce the number of monkey needed to supply cells. Here, we report an in vitro culture system of ICSI-derived zygotes and the establishment of a novel ES cell line in the African green monkey. We believe that AgMES cells would be a precious resource for biomedical research in addition to other primate ES cell lines.

\section{Results}

\section{In vitro culture of ICSI-derived embryos}

Blastocyst stage embryos were prepared from zygotes produced by ICSI as described in our previous report (Shimozawa et al. 2007). A total of 68 zygotes with two pronuclei and a second polar body were cultured with or
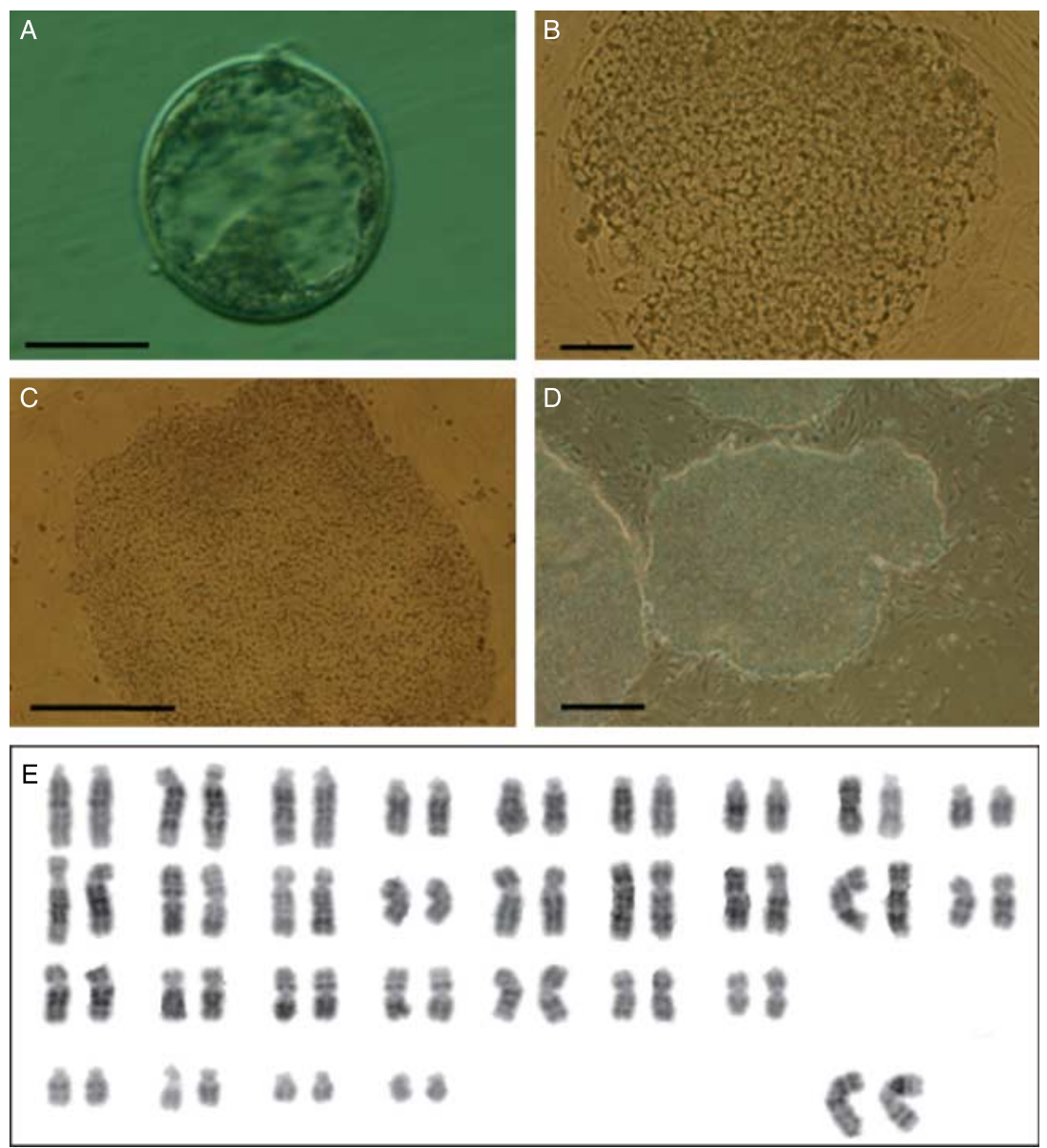

Figure 1 Establishment of the AgMES cell line. Parts of the inner cell mass isolated from an ICSI-derived blastocyst (A) were transferred onto a mitomycin C-treated MEF cell monolayer, which then formed an outgrowth (B). At the first passage dividing the outgrowth into small clusters with collagenase and needles, a new colony appeared $(\mathrm{C})$ and was passaged further. The colonies formed multiple new colonies (D). Hereafter, these colonies were regularly passaged with collagenase and pipetting. Karyotyping analysis revealed that cells examined at passage 19 had a normal chromosome number of 60 and sex chromosomes of XX (E). Bar represents $100 \mu \mathrm{m}(\mathrm{A}$ and $\mathrm{B})$ and $500 \mu \mathrm{m}(\mathrm{C}$ and $\mathrm{D})$. 
without BRL cell monolayer or MEF cell monolayer, and then nine of those developed to the blastocyst stage. Culturing with and without the MEF cell monolayer yielded development to the blastocyst stage, while culturing with the BRL cell monolayer yielded no development $(3 / 14,21.4 \%$ and $6 / 31,19.4 \%$ vs $0 / 23$, $0 \%$ respectively; $P<0.05)$.

\section{Establishment of ES cells}

Nine blastocysts were used to establish ES cells (Table 1). Parts of the ICM isolated by removing the trophectoderm (TE) and the zona pellucida (ZP) with needles (one blastocyst cultured with MEF, hereafter designated I, Fig. 1A; and three without MEF, designated III) or the blastocysts in which the ZP was dissolved with an enzyme (two blastocysts with MEF, designated II; and three without MEF, designated IV) were transferred to ES cell culture medium (ESM) with mitomycin C-treated STO cell or MEF cell monolayer. Of nine blastocysts, four formed outgrowths (one of I blastocysts: Fig. 1B, two of II, and one of III). At the first passage using collagenase and pipetting or dividing into small clusters with needles, three colonies from three outgrowths (one each of I: Fig. 1C, III and IV) appeared and passaged further. The colonies from I passaged with collagenase and needles newly formed multiple colonies (Fig. 1D), but the other colonies passaged with collagenase and pipetting disappeared. Thereafter, these colonies from I were regularly passaged with collagenase and pipetting, and showed flat-formed colony morphology consisting of cells with large nuclei, similar to other primate ES cell lines.

\section{Characterization of undifferentiated ES cells}

We examined karyotype and the expression of undifferentiated markers in the AgMES cell line established. Karyotyping analysis revealed that $88 \%$ (88/100) of cells examined at passage 19 had a normal chromosome number of 60 and sex chromosomes of XX (Fig. 1E). Immunofluoresence revealed that this cell line strongly expressed POU5F1 (Oct-3), TRA-1-60, TRA-1-81, and NANOG, but not SSEA1 (Fig. 2A-E), and showed alkaline phosphatase activity (Fig. 2F). The expression of SSEA3 and SSEA4 was vaguely observed. Furthermore, gene expression analysis of the pluripotency markers by RT-PCR demonstrated that POU5F1 (OCT3/4), NANOG, SOX2, and REX1 were present in AgMES cells, but FOXD3 was not, although three primer sets for FOXD3 were used (Fig. 2G). On the other hand, in CMK6 (AGC Techno Glass Co., Ltd, Chiba, Japan),
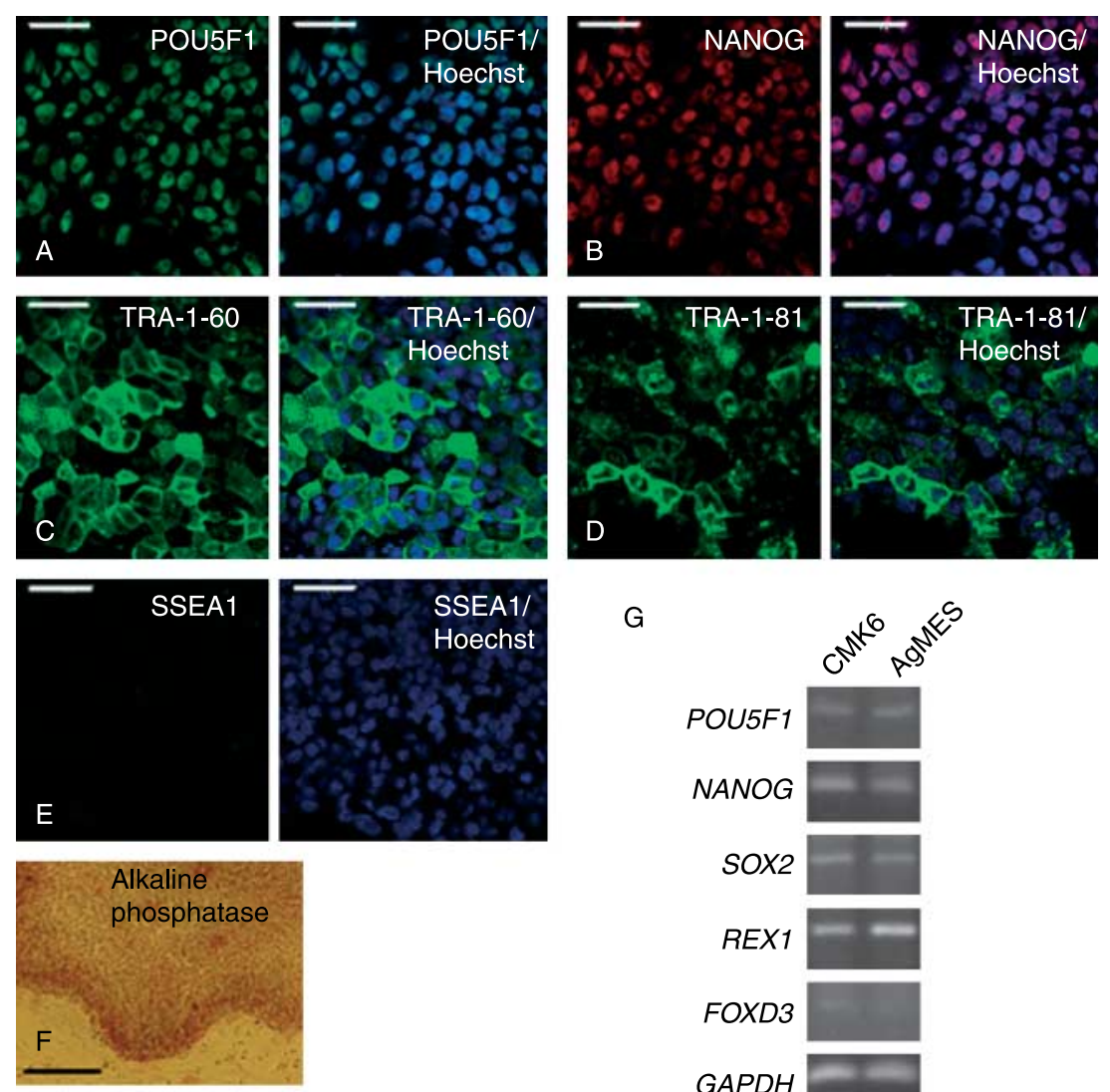

G

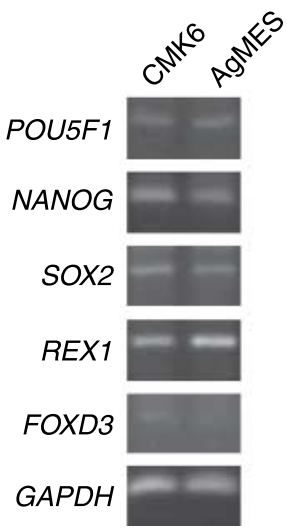

Figure 2 Characterization of undifferentiated AgMES cells. AgMES cells were stained with antibodies against pluripotency markers and alkaline phosphatase (A-F). POU5F1 (A), NANOG (B), TRA-1-60 (C), TRA-1-81 (D), SSEA1 $(\mathrm{E})$, and alkaline phosphatase $(\mathrm{F})$. Nuclei were counterstained with Hoechst 33342 (blue) (A-E). A double staining with POU5F1 (A) and NANOG (B) was conducted in the same specimen. Bar represents $50 \mu \mathrm{m}(\mathrm{A}-\mathrm{E})$ and $200 \mu \mathrm{m}(\mathrm{F})$. Gene expression analysis of pluripotency markers by RT-PCR in AgMES cells was conducted (G).

The results were compared with those for CMK6, a cynomolgus monkey ES cell line established by Suemori et al. (2001), as a control. 
A
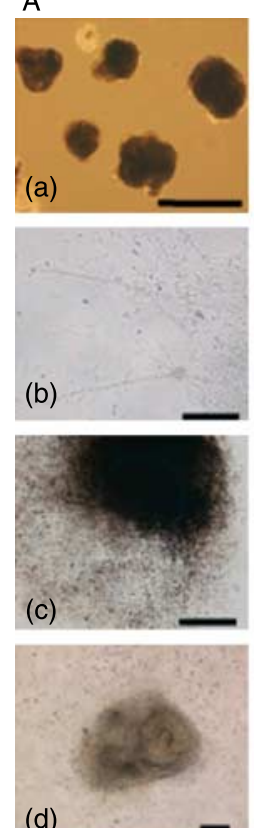

(d)

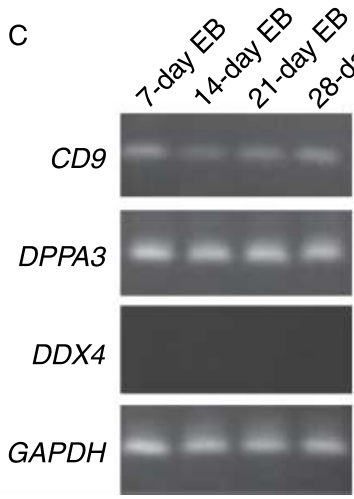

the cynomolgus monkey ES cell line established by Suemori et al. (2001) and employed here as a control, the expression of all markers examined was detected (Fig. 2G).

\section{Pluripotency analysis}

To examine the pluripotency of AgMES cells, we induced the development of embryoid bodies (EBs) and teratomas in vitro and in vivo respectively. EBs were developed by the floating culture of ES cell colonies recovered with collagenase treatment (Fig. 3A; a). After 2 weeks of culturing, most EBs formed solid type clusters. EBs were transferred to tissue culture dishes and then attached. Attached EBs showed outgrowths and spontaneously formed the various differentiated cells such as neuronlike cells, pigment cells, and beating myocardial-like cells (Fig. 3A; b-d). These spontaneous differentiated cells from EBs showed the expression of $\beta$-tubulin III (ectoderm), $\alpha$-smooth muscle actin (mesoderm), $\boldsymbol{\alpha}$-fetoprotein (endoderm), and CDX2 (TE; Fig. 3A; e-h).
Figure 3 Characterization of derivatives from AgMES cells. (A) EBs (a) at 2 weeks after unattached culture spontaneously differentiated to neuron-like cells (b), pigment cells (c), and myocardial-like cells with beating clusters (d). In the derivatives, the expression of $\beta$-tubulin III (e, ectoderm), $\alpha$-smooth muscle actin ( $f$, mesoderm), $\boldsymbol{\alpha}$-fetoprotein (g, endoderm), and CDX2 (h, trophectoderm) was confirmed. Nuclei were counterstained with Hoechst 33342 (blue) (e-h). Bar represents $250 \mu \mathrm{m}(\mathrm{a}-\mathrm{d})$ and $50 \mu \mathrm{m}(\mathrm{e}-\mathrm{h})$. (B) Histological analysis of teratomas formed from AgMES cells. Characteristic morphologies; neural (ectoderm, a), osseous (mesoderm, b), and gut tissues (endoderm, c) were confirmed. Each figure includes insets for showing high magnification of typical cells, such as neuroblasts (a), osteoblasts with osseous matrix (b), and goblet cells (c). Bars represent $100 \mu \mathrm{m}, 40 \mu \mathrm{m}$ (inset a), and $20 \mu \mathrm{m}$ (inset $\mathrm{b}$ and c). (C) Gene expression analysis of germ cell markers by RT-PCR in EBs at days $7,14,21$, and 28 of culture.

Histological analysis revealed that the ES cells transferred into two immunodeficient mice formed teratomas consisting of neural and dermal tissues as ectoderm (Fig. 3B-a; neural tissue), smooth muscle, osseous, cartilage, fatty, fibrous, and vascular tissues as mesoderm (Fig. 3B-C; osseous tissue), and gut tissue as endoderm tissue (Fig. 3B-e). The teratoma formation rate was $100 \%$ $(2 / 2)$. In EBs at days 7, 14, 21, and 28 of culture, we examined the expression of the germ cell markers $C D 9$, DPPA3 (STELLA), and DDX4 (VASA) by RT-PCR. Expression of CD9 and DPPA3 was detected in all samples, while $D D X 4$ was not, although two primer sets for $D D X 4$ were used (Fig. 3C).

\section{Characterization of single-cell subcultured ES cells}

To further characterize the AgMES cell line, we examined whether this cell line could be subcultured by dividing it into single cells with trypsin. The average replating efficiency and rate of colonies with undifferentiated morphology until 52 passages were $20.2 \pm 5.7$ 
A
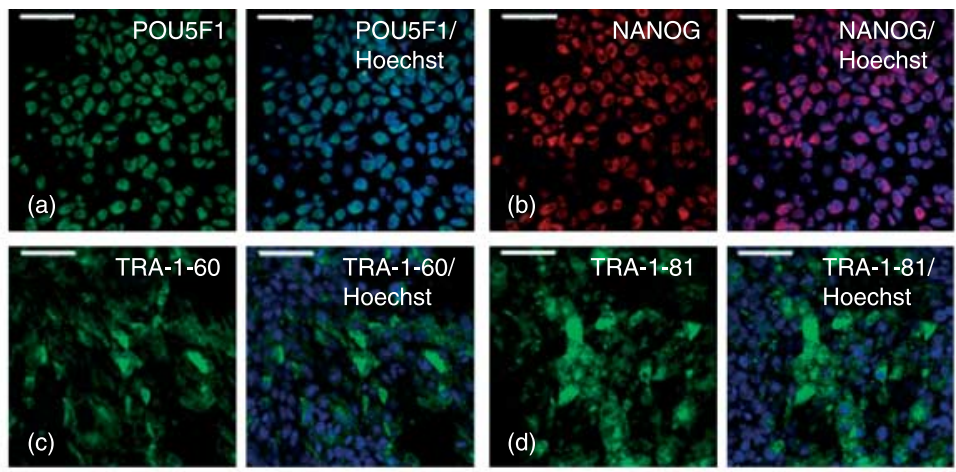

B
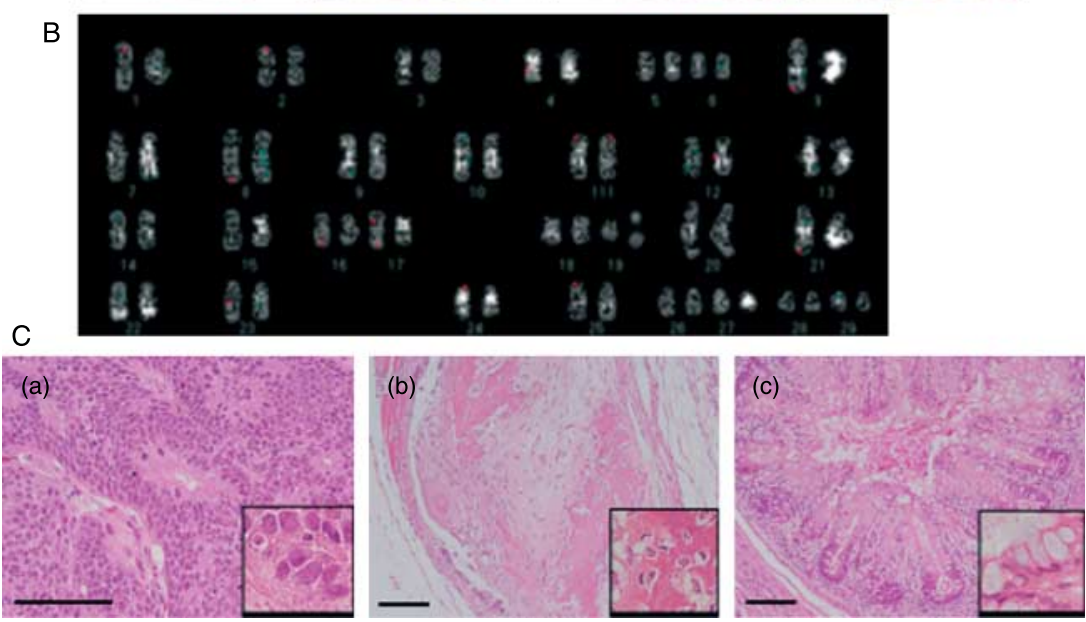

Figure 4 Characterization of single-cell subcultured AgMES cells. (A) The expression of the pluripotency markers, POU5F1 (a), NANOG (b), TRA-1-60 (c), and TRA-1-81 (d), was confirmed. Nuclei were counterstained with Hoechst 33342 (blue) (a-d). A double staining with POU5F1 (a) and NANOG (b) was conducted in the same specimen. Bar represents $50 \mu \mathrm{m}$. (B) Karyotyping of single-cell subcultured AgMES cells. At passage $34,80 \%(40 / 50)$ of the single-cell subcultured AgMES cells had a normal karyotype (60 chromosomes, XX). (C) Histological analysis of teratomas formed from single-cell subcultured AgMES cells. The teratomas showed neural (ectoderm, a), osseous (mesoderm, b), and gut (endoderm, c) tissues. Each figure includes insets for showing high magnification of typical cells, such as neuroblasts (a), osteoblasts with osseous matrix (b), and goblet cells (c). Bars represent $100 \mu \mathrm{m}, 40 \mu \mathrm{m}$ (inset a), and $20 \mu \mathrm{m}$ (inset b and c). and $15.4 \pm 5.8 \%$ respectively and $74.5 \pm 13.8 \%$ of the subcultured single cells formed the undifferentiated colonies. Immunofluorescence revealed that this cell line strongly expressed POU5F1, TRA-1-60, TRA-1-81, and NANOG but not SSEA1 (Fig. 4A). Karyotyping analysis revealed that $80 \%(40 / 50)$ of cells examined at passage 34 after single-cell subculture had a normal chromosome number of 60 (Fig. 4B). Histological analysis revealed that teratomas by single-cell subcultured ES cells in two immunodeficient mice consisted of three embryonic germ layer tissues, e.g. neural and dermal tissues as ectoderm (Fig. 4C-a; neural tissue), musculoskeletal, fatty, fibrous, and vascular tissues as mesoderm (Fig. 4C-b; osseous tissue), and gut tissue as endoderm tissue (Fig. 4C-c). The teratoma formation rate was $100 \%(2 / 2)$.

\section{Discussion}

We examined in vitro culturing of ICSI-derived zygotes and the establishment of an ES cell line, rather than examining developmental potential to term, in the African green monkey. As a result, we succeeded in developing the zygotes to the blastocyst stage and were able to establish a novel primate ES cell line from nine of the blastocysts. The cells derived from African green monkeys are utilized in many types of research and tests.
Therefore, it is expected that the AgMES cell line described in this report could contribute to these applications as a novel biological resource.

Reproductive technologies in the African green monkey have hardly been reported. Development to the blastocyst stage was only reported by in vitro culture in a simple medium following production of the fertilized eggs with IVF in 1997 (Sankai et al. 1997). We reported follicle growth stimulus methods and the fertilization ability by ICSI in 2007 (Shimozawa et al. 2007). Herein, we examined an in vitro culture system using zygotes produced by ICSI. In vitro culturing with and without a MEF cell monolayer supported development to the blastocyst stage, while culturing with a BRL cell monolayer did not. Although a BRL cell monolayer supported development to the blastocyst stage of rhesus monkey embryos (Zhang et al. 1994, Nusser et al. 2001), the reason for this negative effect by BRL cells in African green monkey embryos in the present study is uncertain. On the other hand, the ES cell line was established from the blastocysts that originated from the culture system with the MEF cell monolayer. The number of cells constituting the blastocysts or their ICMs could not be examined because we gave priority to the establishment of the ES cell line. Consequently, it was impossible to compare effects between the culture systems in detail. However, one of the reasons for the successful 
establishment of an ES cell line may have been that MEF cells greatly affected the quality of the ICM.

The novel established AgMES cell line showed characteristics similar to those of other primate ES cell lines (Thomson et al. 1995, 1996, 1998, Suemori et al. 2001). The ratio of nuclei to the cytoplasm in an ES cell was very high, and the colony morphology was flat. Expression of the primate ES cell-specific markers was confirmed by immunofluorescence staining and RT-PCR analysis, and we confirmed that ES cells spontaneously differentiated into three embryonic germ cells via the EBs under in vitro culturing and formed teratomas that consisted of three embryonic germ cells by being transplanted to SCID mice. In addition, $88 \%$ of the examined cells had maintained the normal chromosome number of 60 . As described above, the cell line established herein demonstrated that it is an exact match to the ES cell line.

Immunofluoresence revealed that AgMES vaguely expressed SSEA3 and SSEA4. This may be due to antibodies not suitable for African green monkey epitopes. However, it is possible that expressions of SSEA3 and SSEA4 are not indispensable for ES cells (Brimble et al. 2007). The cynomolgus monkey ES cells are used for basic experiments aimed at application in regenerative medicine (Sánchez-Pernaute et al. 2005, Takagi et al. 2005, Shibata et al. 2006, Osakada et al. 2008). Reports of the differentiation from cynomolgus monkey ES cells to various types of cell suggest that the expression of SSEA3 may not be necessary.

The gene expression analysis also showed that AgMES cells were positive for POU5F1, NANOG, SOX2, and REX1. The expression of FOXD3 was not detected, despite the use of three primer sets for FOXD3. However, in $\mathrm{EB}$, the expression of FOXD3 was detected (data not shown). It has been reported that FOXD3 has the antagonistic effect on POU5F1 (Guo et al. 2002) and was not expressed in undifferentiated human and common marmoset ES cells (Ginis et al. 2004, Mandal et al. 2006, Müller et al. 2009). We demonstrated that FOXD3 of African green monkey was not expressed in undifferentiated cells but was detected during differentiation the same as human and common marmoset. In addition, a difference in the gene expression of the pluripotency marker REX1 in ES cells has been observed among species. REX1 expression has been detected in human ES cells (Ginis et al. 2004, Mandal et al. 2006) but not in rhesus monkey ES cells (Mitalipov et al. 2006). In the present study, both of African green and cynomolgus monkey ES cells expressed REX1, suggesting that the characterization of different ES cell lines within the same species may differ.

Several researchers have examined the differentiation of primate ES cells into germ cells (Clark et al. 2004, Chen et al. 2007, Sparman et al. 2009). When we examined the expression of three germ cell markers, CD9, DPPA3, and DDX4, in EBs derived from AgMES cells by RT-PCR, the expression of CD9 and DPPA3 was detected. This suggested that AgMES cells might have the potential ability to differentiate into germ cells, although further study is necessary. Differentiation into germ cells may be enabled in the primates by doing the comparative study using primate and mouse ES cell lines. Additionally, it was reported that epiblast stem cells (EpiSCs) established in mice did not possess the ability to differentiate into germ cells in vivo (Brons et al. 2007, Tesar et al. 2007). Primate ES cells may also lack the potential to differentiate into germ cells because EpiSCs show characteristics similar to primate ES cells such as culture condition and colony morphology. However, it is unclear whether primate ES cells can differentiate into germ cells. It will thus be very important to study the differentiation of nonhuman primate ES cells into germ cells both in vivo and in vitro. We consider that the AgMES cells could become a highly valuable research tool as well as rhesus, cynomolgus, and common marmoset monkey ES cell lines.

Next, we examined whether single AgMES cells can continuously be passaged. When the subcultures of single ES cells dissolved with trypsin were repeated 52 times, a replating rate of $20.2 \%$ and an undifferentiation colony formation rate of $15.4 \%$ were obtained. These ES cells were positive for the primate ES cell-specific markers, formed teratomas, and had normal karyotype, which demonstrated that the AgMES cells maintained by the single-cell subculture method had the same characteristics of undifferentiation and pluripotency. Human ES cell lines were difficult to continue to subculture by single cells, and because the undifferentiation colony formation rate was $\sim 1 \%$. Improvements of culture environment by using some feeder cells or chemical compounds have been examined (Amit et al. 2000, Hasegawa et al. 2006, Ellerström et al. 2007, Watanabe et al. 2007). However, single AgMES cells showed $15 \%$ of the undifferentiation colony formation rate in the same culture environment as the subculture by small clusters. The AgMES cell line has the potential for easy application in various examinations under in vitro culture and to contribute to the research into the proliferation mechanisms underlying colony formation from a single cell in the primate ES cells.

The primary culture cells or the Vero cells that originate from the kidney of the African green monkey have been used for applications such as vaccine developments and virus inspections. In addition, the red blood cells of the African green monkey are used for the measles virus test. We think that studies of the erythropoiesis or hematopoiesis differentiation in cynomolgus ES cells might be able to contribute to differentiation of the red blood cells from AgMES (Hiroyama et al. 2006, Umeda et al. 2006). The characteristics and chromosomes of kidney-derived cells may have mutated naturally by repeating the subculture for a long time. Inducing differentiation of 
pluripotent ES cells, whose chromosomes are relatively steady compared with the various cell lines, may facilitate their becoming a source of cells with uniform properties. This shows the possibility that the red blood cells and the cells of kidney differentiated from the AgMES cells may become a substitute for cells from living monkeys. Producing the various cells from the ES cells would alleviate the need to collect the cells from living animals.

\section{Materials and Methods}

\section{Animals}

The mature African green monkeys ( $C$. aethiops) used in this study were bred and maintained in an air-conditioned room with controlled illumination (12 h light: $12 \mathrm{~h}$ darkness), temperature $\left(25 \pm 2{ }^{\circ} \mathrm{C}\right)$, humidity $(60 \pm 5 \%)$, and ventilation (10 cycles/h), and were given $70 \mathrm{~g}$ of commercial food (Type AS; Oriental Yeast Co., Ltd, Tokyo, Japan) and $100 \mathrm{~g}$ of apples daily, and unlimited access to tap water at the Tsukuba Primate Research Center (Tsuchida et al. 2008). Every morning, the health condition (e.g. viability, appetite, fur-coat appearance) and menstruation status of each female monkey were monitored. For ovarian stimulation, eight female monkeys were used. Maintenance of animals was conducted according to the guidelines set by the National Institutes of Biomedical Innovation (NIBIO) for the care, use, and biohazard countermeasures of laboratory animals. This study was approved by the Animal Welfare and Animal Care Committee of NIBIO.

\section{Ovarian stimulation and oocyte collection}

For ovarian stimulation, the administration of human FSH (hFSH: Fertinorm, Merck Serono), equine chorionic gonadotropin (eCG: Serotropin, ASKA Pharmaceutical, Tokyo, Japan), or human menopausal gonadotropin (hMG) followed by human chorionic gonadotropin (hCG: Gonatropin, ASKA Pharmaceutical) was conducted. Protocols of hFSH and eCG administration, and oocyte collection were reported previously (Shimozawa et al. 2007). Briefly, on the first day of menstruation, the female monkeys were administered leuprorelin acetate s.c. as a GNRH agonist (GNRHa; Leuplin, Takeda Pharmaceutical, Osaka, Japan). At 2-3 weeks after that, the follicular growth of these monkeys was stimulated by $25 \mathrm{IU} / \mathrm{kg}$ per day hFSH administered for 9 days, $200 \mathrm{IU} /$ head per day eCG administered i.m. for 6 days, or $37.5 \mathrm{IU} /$ head per day hMG administered i.m. daily for 6 days. Thirty-six hours after the final hFSH, eCG, or hMG administration, $1200 \mathrm{IU} /$ head hCG was administered. At 36-38 h after hCG administration, females were anesthetized by $10 \mathrm{mg} / \mathrm{kg}$ ketamine hydrochloride (Ketalar, Bayer Yakuhin) and $1 \mathrm{mg} / \mathrm{kg}$ xylazine hydrochloride (Seractarl, Bayer Yakuhin) administration. Ovaries were exposed through an abdominal incision, and the contents of the follicles were aspirated through a 25-gauge needle. The collected follicular contents were immediately placed in TYH medium modified by adding Hepes (HepesTYH) containing $2.5 \mathrm{IU} / \mathrm{ml}$ heparin (Novo Nordisk Pharma, Tokyo, Japan). The oocytes were freed from cumulus cells by pipetting after treatment with $0.1 \%$ hyaluronidase (Sigma) in Hepes-TYH medium. Collected oocytes were then transferred to CMRL-1066 (Invitrogen) medium containing 10\% fetal bovine serum (FBS, Hyclone, Logan, UT, USA), Gluta-MAX ( $\times 100$, Invitrogen), and penicillin-streptomycin solution ( $\times 100$, Sigma), hereafter simply called CMRL.

\section{ICSI and embryo culture}

Sperm collection and ICSI were performed as described previously (Shimozawa et al. 2007). Briefly, fresh semen was collected in TYH medium by rectal probe electrostimulation. Semen suspension was layered onto 90\% Percoll (GE Healthcare UK Ltd, Buckinghamshire, England) diluted with $9 \% \mathrm{NaCl}$ solution and then centrifuged at $800 \mathrm{~g}$ for $10 \mathrm{~min}$. The precipitate containing sperm was suspended in CZB modified by adding Hepes (Hepes-CZB). Sperm suspended in Hepes-CZB with 10\% polyvinylpyrrolidone (Sigma) was used for ICSI. Mature oocytes with a polar body were subjected to ICSI using a micromanipulation system equipped with a piezo drive unit (Primetech, Ibaraki, Japan) under an inverted microscope (Nikon, Tokyo, Japan). An immobilized spermatozoon drawn into the injection pipette was injected into the mature (MII) oocyte by using a few piezo pulses, and then injected oocytes were transferred into CMRL microdroplets. The fertilized embryos were judged to be normal based on the formation of two pronuclei and the release of a second polar body 15-16 h after ICSI. Embryos were cultured with or without a MEF cell monolayer or a BRL cell monolayer in $500 \mu \mathrm{l} \mathrm{CMRL} \mathrm{using} \mathrm{a} \mathrm{four-well} \mathrm{multidish} \mathrm{(Nunc,} \mathrm{Rochester,}$ Denmark). Half of the CMRL was changed every other day. Culturing was performed under CMRL covered with mineral oil at $37.5{ }^{\circ} \mathrm{C}$ in a humidified atmosphere of $5 \% \mathrm{CO}_{2}, 5 \% \mathrm{O}_{2}$, and $90 \%$ air.

\section{Establishment of ES cells}

The TE and ZP of blastocysts were removed mechanically with 27-G needles or dissolved in the ZP with $0.5 \%$ actinase. Treated blastocysts were cultured with mitomycin C-treated STO cell or MEF cell monolayer on gelatin-coated dishes in ESM consisting of DMEM/F12 (1:1) supplemented with 20\% knockout serum replacement (KSR, Invitrogen), 1\% GlutaMax (Invitrogen), $0.1 \mathrm{mM} \quad \beta$-mercaptethanol (Sigma), $1 \%$ nonessential amino acids (Invitrogen), and $10 \mathrm{ng} / \mathrm{ml}$ human recombinant leukemia inhibitory factor (hLIF, Millipore, Billerica, MA, USA). In one case, ESM in which FBS replaced KSR and that was supplemented with $4 \mathrm{ng} / \mathrm{ml}$ human recombinant basic fibroblast growth factor (hbFGF, Wako Pure Chemical Industries, Ltd, Osaka, Japan) was used. The extended colony was treated with $0.1 \%$ collagenase (Wako) in DMEM (Sigma) and divided mechanically into small clusters with pipetting or with 27-G needles, then passaged onto a new feeder layer. The resulting stem cell colony was expanded using $0.1 \%$ collagenase and passaged with pipetting or 27-G needles into a 6-cm dish (BD Falcon, Franklin Lakes, NJ, USA). ES cell colonies were divided into small clusters using $0.1 \%$ collagenase and pipetting. 
Table 2 Primer sequences used for RT-PCR analyses.

\begin{tabular}{|c|c|c|c|}
\hline Gene & Forward & Reverse & bp \\
\hline POU5F1 & TTGGAGACCTCTCAGCCTGA & ACACATGTTCTTGAAGCTAA & 326 \\
\hline SOX2 & CCCCCGGCGGCAAC GCA & TCGGCGCCGGGGAGATACAT & 448 \\
\hline NANOG & CAGAAGGCCTCAGCACCTAC & GACTGTTCCAGGCCTGATTGTT & 217 \\
\hline REX1 & CAGATCGAAAACAGCTCGCAGAAT & CGTACGCAAATTGAAGTCCAGG & 305 \\
\hline FOXD3 & TACATCGCGCTCATCACCATG & GTTGTCGAACATGTCCTCGGA & 246 \\
\hline CD9 & AAATAGCTGCGGCCATCTGGGGATA & G CCСССАGCCAAACCACAGCA & 167 \\
\hline DPPA3 & GTTACTCGGCAGAGTTCGTA & TGAAGTGGCTTGGTGTCGTA & 167 \\
\hline$D D \times 4$ & AGGATGAGGACTCCATCTTTGCACATTAT & САGАСССТGTTTGAGCACAAGCСА & 252 \\
\hline GAPDH & TGGACCTGACCTGCCGTCT & GGAAGAGTGGGTGTCGCTGT & 152 \\
\hline
\end{tabular}

For the investigation of undifferentiated colony formation from a single ES cell, ES cell colonies recovered after collagenase treatment were dispersed to single cells with $0.25 \%$ tryp$\sin / 0.1 \mathrm{~m}$ EDTA (Sigma), and a thousand single ES cells were cultured with MEF cell monolayer in a $3.5-\mathrm{cm}$ dish (BD Falcon).

\section{Characterization}

Alkaline phosphatase was detected using Alkaline Phosphatase Chromogen Kit (Biomeda, Plovdiv, Bulgaria). For immunofluorescence, cells were fixed with $4 \%$ paraformaldehyde in PBS for $20 \mathrm{~min}$. Following permeabilization with $0.2 \%$ Triton X-100 in PBS for 10 min and blocking with $5 \%$ skim milk in PBS for $30 \mathrm{~min}$, cells were incubated with primary antibodies overnight at $4{ }^{\circ} \mathrm{C}$ and visualized by $\lg \mathrm{G}$ or IgM conjugated with Alexa 488 (A11001, A21042, and A21212) or 555 (A21428) (1:1000, Invitrogen). Primary antibodies used were as follows: POU5F1 (1:50, 611202; BD Biosciences, San Jose, CA, USA), NANOG (1:50, RCAB0003P, ReproCELL Inc., Tokyo, Japan), SSEA1 (MAB4301), SSEA3 (MAB4303), SSEA4 (MAB4304), TRA-1-60 (MAB4360), TRA-1-81 (MAB4381) (1:80, Millipore), Nestin (1:50, MAB1259), $\alpha$-smooth muscle actin (1:100, MAB1420, R\&D Systems, Minneapolis, MN, USA), $\beta$-tubulin III (1:50, T 8660), $\alpha$-fetoprotein $(1: 500, A$ 8452, Sigma), and CDX2 (1:100, GTX15258, GeneTex, San Antonio, TX, USA). The nuclei were stained with $10 \mu \mathrm{g} / \mathrm{ml}$ Hoechst 33342 (Calbiochem, Darmstadt, Germany) in PBS.

For pluripotency analysis, EBs and teratomas were prepared from ES cells. EBs were grown by culturing unattached ES cell colonies in ESM without hLIF and hbFGF. After 2 weeks, EBs were transferred to 6-cm dishes in DMEM containing 10\% FBS for attachment culture. Spontaneous differentiated cells from EB were observed and analyzed by immunofluorescence. Teratoma formation was as follows: six $6-\mathrm{cm}$ dishes of small cluster subcultured and single-cell subcultured ES cells suspended in ESM without hLIF and hbFGF were injected into the hind leg muscle of two immunodeficient mice (NOD/SCID, Charles River Japan, Kanagawa, Japan) respectively. Tumors were fixed with $4 \%$ paraformaldehyde in PBS, then embedded in paraffin, and sectioned for histological analysis by hematoxylin and eosin staining. No tumors formed in two NOD/SCID mice that were injected with ESM without hLIF and hbFGF as a control.

Karyotype analyses were performed at the International Council for Laboratory Animal Science Monitoring Center (Kanagawa, Japan) or the Chromosome Science Labo Inc (Hokkaido, Japan).

\section{Gene expression analysis}

Undifferentiated AgMES cells and EBs at days 7, 14, 21, and 28 of culture were treated with RNAlater (Ambion, Austin, TX, USA). RNA was isolated using an RNAqueous Kit (Ambion) according to the manufacture's protocol. First-strand cDNA was primed via random hexamers, and RT-PCR was performed with the primer sets showing in Table 2. The expected sizes of the PCR products were inferred from rhesus monkey and human sequences.

\section{Statistical analysis}

Data were analyzed using Fisher's exact probability test. $P<0.05$ was considered significant.

\section{Declaration of interest}

The authors declare that there is no conflict of interest that could be perceived as prejudicing the impartiality of the research reported.

\section{Funding}

This study was supported by grants from the Ministry of Health, Labor and Welfare of Japan.

\section{Acknowledgements}

We are grateful to the staff of the Corporation for Production and Research of Laboratory Primates for their kind cooperation in the collection of samples.

\section{References}

Amit M, Carpenter MK, Inokuma MS, Chiu CP, Harris CP, Waknitz MA, Itskovitz-Eldor J \& Thomson JA 2000 Clonally derived human embryonic stem cell lines maintain pluripotency and proliferative potential for prolonged periods of culture. Developmental Biology 227 271-278.

Brimble SN, Sherrer ES, Uhl EW, Wang E, Kelly S, Merrill AH Jr, Robins AJ \& Schulz TC 2007 The cell surface glycosphingolipids SSEA-3 and SSEA4 are not essential for human ESC pluripotency. Stem Cells 25 54-62.

Brons IG, Smithers LE, Trotter MW, Rugg-Gunn P, Sun B, Chuva de Sousa Lopes SM, Howlett SK, Clarkson A, Ahrlund-Richter L, Pedersen RA et al. 2007 Derivation of pluripotent epiblast stem cells from mammalian embryos. Nature 448 191-195.

Chen HF, Kuo HC, Chien CL, Shun CT, Yao YL, Ip PL, Chuang CY, Wang CC, Yang YS \& Ho HN 2007 Derivation, characterization and differentiation 
of human embryonic stem cells: comparing serum-containing versus serum-free media and evidence of germ cell differentiation. Human Reproduction 22 567-577.

Clark AT, Bodnar MS, Fox M, Rodriquez RT, Abeyta MJ, Firpo MT \& Pera RA 2004 Spontaneous differentiation of germ cells from human embryonic stem cells in vitro. Human Molecular Genetics 13 727-739.

Ellerström C, Strehl R, Noaksson K, Hyllner J \& Semb H 2007 Facilitated expansion of human embryonic stem cells by single-cell enzymatic dissociation. Stem Cells 25 1690-1696.

Ginis I, Luo Y, Miura T, Thies S, Brandenberger R, Gerecht-Nir S, Amit M, Hoke A, Carpenter MK, Itskovitz-Eldor J et al. 2004 Differences between human and mouse embryonic stem cells. Developmental Biology 269 360-380.

Guo Y, Costa R, Ramsey H, Starnes T, Vance G, Robertson K, Kelley M, Reinbold R, Scholer H \& Hromas R 2002 The embryonic stem cell transcription factors Oct-4 and FoxD3 interact to regulate endodermalspecific promoter expression. PNAS 99 3663-3667.

Hasegawa K, Fujioka T, Nakamura Y, Nakatsuji N \& Suemori H 2006 A method for the selection of human embryonic stem cell sublines with high replating efficiency after single-cell dissociation. Stem Cells $\mathbf{2 4}$ 2649-2660.

Hiroyama T, Miharada K, Aoki N, Fujioka T, Sudo K, Danjo I, Nagasawa T \& Nakamura Y 2006 Long-lasting in vitro hematopoiesis derived from primate embryonic stem cells. Experimental Hematology 34 760-769.

Mandal A, Tipnis S, Pal R, Ravindran G, Bose B, Patki A, Rao MS \& Khanna A 2006 Characterization and in vitro differentiation potential of a new human embryonic stem cell line, ReliCellhES1. Differentiation $\mathbf{7 4}$ 81-90.

Mitalipov S, Kuo HC, Byrne J, Clepper L, Meisner L, Johnson J, Zeier R \& Wolf D 2006 Isolation and characterization of novel rhesus monkey embryonic stem cell lines. Stem Cells 24 2177-2186.

Müller T, Fleischmann G, Eildermann K, Mätz-Rensing K, Horn PA, Sasaki E \& Behr R 2009 A novel embryonic stem cell line derived from the common marmoset monkey (Callithrix jacchus) exhibiting germ cell-like characteristics. Human Reproduction 24 1359-1372.

Nakamura S, Okabayashi S, Ageyama N, Koie H, Sankai T, Ono F, Fujimoto K \& Terao K 2008 Transthyretin amyloidosis and two other aging-related amyloidoses in an aged vervet monkey. Veterinary Pathology 45 67-72.

Nusser KD, Mitalipov S, Widmann A, Gerami-Naini B, Yeoman RR \& Wolf DP 2001 Developmental competence of oocytes after ICSI in the rhesus monkey. Human Reproduction 16 130-137.

Osakada F, Ikeda H, Mandai M, Wataya T, Watanabe K, Yoshimura N, Akaike A, Sasai Y \& Takahashi M 2008 Toward the generation of rod and cone photoreceptors from mouse, monkey and human embryonic stem cells. Nature Biotechnology 26 215-224.

Sánchez-Pernaute R, Studer L, Ferrari D, Perrier A, Lee H, Viñuela A \& Isacson $\mathbf{O} 2005$ Long-term survival of dopamine neurons derived from parthenogenetic primate embryonic stem cells (cyno-1) after transplantation. Stem Cells 23 914-922.

Sankai T, Cho F \& Yoshikawa Y 1997 In vitro fertilization and preimplantation embryo development of African green monkeys (Cercopithecus aethiops). American Journal of Primatology 43 43-50.
Shibata H, Ageyama N, Tanaka Y, Kishi Y, Sasaki K, Nakamura S, Muramatsu S, Hayashi S, Kitano Y, Terao K et al. 2006 Improved safety of hematopoietic transplantation with monkey embryonic stem cells in the allogeneic setting. Stem Cells 24 1450-1457.

Shimozawa N, Okada H, Hatori M, Yoshida T \& Sankai T 2007 Comparison of methods to stimulate ovarian follicular growth in cynomolgus and African green monkeys for collection of mature oocytes. Theriogenology 67 1143-1149.

Sparman M, Dighe V, Sritanaudomchai H, Ma H, Ramsey C, Pedersen D, Clepper L, Nighot P, Wolf D, Hennebold J et al. 2009 Epigenetic reprogramming by somatic cell nuclear transfer in primates. Stem Cells 27 1255-1264.

Suemori H, Tada T, Torii R, Hosoi Y, Kobayashi K, Imahie H, Kondo Y, Iritani A \& Nakatsuji N 2001 Establishment of embryonic stem cell lines from cynomolgus monkey blastocysts produced by IVF or ICSI. Developmental Dynamics 222 273-279.

Takagi Y, Takahashi J, Saiki H, Morizane A, Hayashi T, Kishi Y, Fukuda H, Okamoto Y, Koyanagi M, Ideguchi $\mathbf{M}$ et al. 2005 Dopaminergic neurons generated from monkey embryonic stem cells function in a Parkinson primate model. Journal of Clinical Investigation 115 102-109.

Tesar PJ, Chenoweth JG, Brook FA, Davies TJ, Evans EP, Mack DL, Gardner RL \& McKay RD 2007 New cell lines from mouse epiblast share defining features with human embryonic stem cells. Nature $\mathbf{4 4 8}$ 196-199.

Thomson JA, Kalishman J, Golos TG, Durning M, Harris CP, Becker RA \& Hearn JP 1995 Isolation of a primate embryonic stem cell line. PNAS 92 7844-7848.

Thomson JA, Kalishman J, Golos TG, Durning M, Harris CP \& Hearn JP 1996 Pluripotent cell lines derived from common marmoset (Callithrix jacchus) blastocysts. Biology of Reproduction 55 254-259.

Thomson JA, Itskovitz-Eldor J, Shapiro SS, Waknitz MA, Swiergiel JJ, Marshall VS \& Jones JM 1998 Embryonic stem cell lines derived from human blastocysts. Science 282 1145-1147.

Tsuchida J, Yoshida T, Sankai T \& Yasutomi Y 2008 Maternal behavior of laboratory-born, individually reared long-tailed macaques (Macaca fascicularis). Journal of the American Association for Laboratory Animal Science 47 29-34.

Umeda K, Heike T, Nakata-Hizume M, Niwa A, Arai M, Shinoda G, Ma F, Suemori H, Luo HY, Chui DH et al. 2006 Sequential analysis of $\alpha$ - and $\beta$-globin gene expression during erythropoiesis differentiation from primate embryonic stem cells. Stem Cells 24 2627-2636.

Watanabe K, Ueno M, Kamiya D, Nishiyama A, Matsumura M, Wataya T, Takahashi JB, Nishikawa S, Nishikawa S, Muguruma K et al. 2007 A ROCK inhibitor permits survival of dissociated human embryonic stem cells. Nature Biotechnology 25 681-686.

Zhang L, Weston AM, Denniston RS, Goodeaux LL, Godke RA \& Wolf DP 1994 Developmental potential of rhesus monkey embryos produced by in vitro fertilization. Biology of Reproduction 51 433-440.

Received 22 February 2009

First decision 23 March 2009

Revised manuscript received 24 November 2009

Accepted 1 December 2009 